Review Article

\title{
Genomic imbalances in esophageal squamous cell carcinoma identified by molecular cytogenetic techniques
}

\author{
Marilanda Ferreira Bellini ${ }^{1,2}$, Ana Elizabete Silva ${ }^{1}$ and Marileila Varella-Garcia ${ }^{2}$ \\ ${ }^{1}$ Laboratório de Citogenética e Biologia Molecular, Departamento de Biologia, Universidade Estadual \\ Paulista 'Júlio de Mesquita Filho', Campus São José do Rio Preto, SP, Brazil. \\ ${ }^{2}$ Medicine/Medical Oncology, Health Sciences Center, University of Colorado, Aurora, CO, USA.
}

\begin{abstract}
This review summarizes the chromosomal changes detected by molecular cytogenetic approaches in esophageal squamous cell carcinoma (ESCC), the ninth most common malignancy in the world. Whole genome analyses of ESCC cell lines and tumors indicated that the most frequent genomic gains occurred at 1, 2q, 3q, 5p, 6p, 7, 8q, 9q, $11 q, 12 p, 14 q, 15 q, 16,17,18 p, 19 q, 20 q, 22 q$ and $X$, with focal amplifications at 1q32, 2p16-22, 3q25-28, 5p13-15.3, 7p12-22, 7q21-22, 8q23-24.2, 9q34, 10q21, 11p11.2, 11q13, 13q32, 14q13-14, 14q21, 14q31-32, 15q22-26, 17p11.2, 18p11.2-11.3 and 20p11.2. Recurrent losses involved 3p, 4, 5q, 6q, 7q, 8p, 9, 10p, 12p, 13, 14p, 15p, 18, $19 p, 20,22, X p$ and $Y$. Gains at $5 p$ and $7 q$, and deletions at $4 p, 9 p$, and 11q were significant prognostic factors for patients with ESCC. Gains at $6 p$ and 20p, and losses at $10 p$ and $10 q$ were the most significant imbalances, both in primary carcinoma and in metastases, which suggested that these regions may harbor oncogenes and tumor suppressor genes. Gains at $12 p$ and losses at $3 p$ may be associated with poor relapse-free survival. The clinical applicability of these changes as markers for the diagnosis and prognosis of ESCC, or as molecular targets for personalized therapy should be evaluated.
\end{abstract}

Key words: CGH, esophageal carcinoma, FISH, genomic imbalances, molecular cytogenetics.

Received: April 29, 2009; Accepted: October 14, 2009.

\section{Esophageal Carcinoma}

Cancer of the esophagus is the ninth most common malignancy in the world, but its incidence varies considerably among geographical regions (Lam, 2000), with a high incidence in China, Japan, Singapore and Puerto Rico (INCA, 2009a). The American Cancer Society estimated that around 16,470 new cases of esophageal carcinoma occurred in the USA in 2008 (American Cancer Society, 2009). In Brazil, esophageal cancer ranked sixth in cancer mortality in 2000, with 5,307 deaths; about 10,550 new cases were reported in 2008, with an incidence of 1.0419.07 per 1000,000 males and $0.39-7.58$ per 100,000 females (INCA, 2009b).

The development of human esophageal cancer is progressive, involving the accumulation of genetic changes that culminate in malignant transformation (Knudson, 1985; Somers and Schechter, 1992; Xue et al., 2006). An early indicator of this process is the increased proliferation of esophageal epithelial cells that morphologically pro-

Send correspondence to Ana Elizabete Silva. Laboratório de Citogenética e Biologia Molecular, Departamento de Biologia, Universidade Estadual Paulista 'Júlio de Mesquita Filho', Rua Cristóvão Colombo 2265, 15054-000 São José do Rio Preto, SP, Brazil. E-mail: anabete@ibilce.unesp.br. gresses to basal cell hyperplasia, dysplasia, carcinoma in situ and invasive carcinoma (Muñoz, 1997; Mandard et al., 2000; D’Amico, 2006).

With the exception of the USA, esophageal squamous cell carcinoma (ESCC) is histologically the most prevalent type of esophageal cancer worldwide and has a multifactorial origin. In addition to environmental components (Crawford, 2004), several genetic factors are associated with esophageal carcinogenesis, such as chromosomal aneuploidy, allelic deletions, activation of oncogenes and inactivation of tumor suppressor genes (Kuwano et al., 2005). At the cellular level, these factors lead to disorders of cell proliferation, differentiation and apoptosis (Koch et al., 1994; McCabe and Dlamini, 2005; D'Amico, 2006; Daigo and Nakamura, 2008; Khushalani, 2008).

Specific chromosomal aberrations have been identified as markers for the diagnosis and prognosis of solid tumors (Tada et al., 2000; Yen et al., 2001; Shiomi et al., 2003; Qin et al., 2004, 2005a,b, 2008; Wang et al., 2006). Despite reports of numerous chromosomal alterations, no particular diagnostic or prognostic chromosomal markers have been described for esophageal carcinoma. The aim of this review is to summarize the recurrent chromosomal changes, such as gains and losses in regions that may harbor 
oncogenes and tumor suppressor genes that have been detected in ESCC by molecular cytogenetic approaches. These chromosomal imbalances may represent clinically relevant markers for the diagnosis and prognosis of ESCC or for the identification of novel therapeutic targets.

\section{Molecular Cytogenetic Technologies Identify Genomic Changes In Cancer}

The primary cytogenetic technique used to investigate the molecular pathogenesis of esophageal carcinogenesis is DNA fluorescence in situ hybridization (FISH). This technique uses small fragments of DNA as fluorescent probes that bind to specific chromosomal sequences of the target DNA to which they show a high degree of complementarity (Bauman et al., 1980; Langer et al., 1981). FISH probes are often derived from DNA fragments that vary from a few hundred to 200,000 base-pairs; these fragments are isolated, purified, amplified and labeled with fluorochrome-conjugated nucleotides. The DNA probes hybridize to distinct DNA targets such as metaphase chromosomes, interphase nuclei, and extended chromatin fibers and DNA fragments in a variety of biological specimens or platforms, including isolated cells, tissue sections and bacterial artificial chromosomes (BAC) and oligonucleotide arrays (Solinas-Toldo et al., 1997; Pinkel et al., 1998; Speicher and Carter, 2005).

There are numerous variants of the FISH assay, with the most effective for detecting extensive genomic imbalances being comparative genomic hybridization (CGH). $\mathrm{CGH}$ was originally developed as the competitive hybridization of a mixture of test DNA and normal reference DNA, labeled with different fluorochromes, to metaphase spreads of a normal specimen, i.e., metaphase CGH (mCGH) (Kallioniemi et al., 1992; du Manoir et al., 1993). In these conditions, chromosomal regions of the test DNA that have normal copy numbers will show a balanced ratio of hybridization with the test and control DNA, whereas chromosomal regions with an excess or loss of copy numbers in the test DNA will show predominantly the color of the hybridization in the normal template. The test DNA used in the $\mathrm{CGH}$ assay can be extracted from dividing or non-dividing cells from virtually all types of tissues, including formalin-fixed specimens; the latter possibility allows an informative overview of archived specimens. The level of resolution of specific imbalances in the $\mathrm{mCGH}$ assay depends essentially on the condensation of the chromosomes to which the DNA mix is hybridized and ranges from 5 to $10 \mathrm{Mb}$ (Kallioniemi et al., 1992; Speicher and Carter, 2005). Although it is possible to identify large regions involved in low level of genomic gain or loss and small regions with focal amplification, the resolution of the $\mathrm{mCGH}$ is generally limited or insufficient for the identification of specific chromosomal bands (Kallioniemi et al., 1992; Speicher and Carter, 2005). Consequently, mCGH is gener- ally used as a preliminary tool to infer potential genes located in imbalanced regions and to confirm or support the results of studies with higher resolution techniques, such as array $\mathrm{CGH}(\mathrm{aCGH})$ or FISH with single gene probes (Nakakuki et al., 2002; Arai et al., 2003)

The aCGH technique detects changes in chromosome copy number at a much higher resolution than $\mathrm{mCGH}$ (Solinas-Toldo et al., 1997; Pinkel et al., 1998). Instead of using metaphase spreads as the template for hybridization, the aCGH uses a collection of DNA inserts contained in bacterial artificial chromosomes (BAC arrays) or oligonucleotides (oligo-arrays) printed on a glass slide. As with the mCGH, a differentially labeled mixture of DNAs from the test sample and a normal reference control sample is hybridized with the selected platform and the ratio of the fluorescence intensity of the test to reference DNA is calculated. Using aCGH, changes in copy number can be detected based on a few hundred kilobases of DNA sequences for BAC arrays or $30 \mathrm{~kb}$ for oligoarrays (Snijders et al., 2001; Fiegler et al., 2003; Medical Genetics Laboratories, 2008). More recently, imbalances involving single nucleotides have been detected by single nucleotide polymorphism (SNP)-based arrays, a type of DNA microarray used to detect polymorphisms within a population (Sherry et al., 2001).

Other variants of FISH technology include multiplex-FISH (M-FISH) and spectral karyotyping (SKY). These procedures allow identification of the origin of each chromosomal region in a metaphase cell by visualizing all 24 human chromosomes in a single hybridization (Speicher and Carter, 2005). In both techniques, the probe set is a pool of differentially labeled DNAs for each of the 24 human chromosomes. In M-FISH, the images for each fluorochrome are collected individually and merged, and a combinatorial labeling algorithm identifies each chromosome that is then visualized in pre-defined pseudocolor (Speicher et al., 1996). In the SKY assay, a single image is captured per cell and an interferometer is used to discriminate the fluorochrome spectrum in each pixel, to which a pseudocolor is assigned (Schröck et al., 1996). Both techniques have been successful in clarifying complex chromosomal rearrangements in solid tumors (Schröck and Padilla-Nash, 2000), including ESCC (Yen et al., 2003).

Together, the numerous variants of FISH technology have allowed the accurate identification of chromosomal DNA sequences of interest and facilitated the screening of the whole genome for gains and losses associated with carcinogenesis.

\section{Genomic Imbalances In Escc Cell Lines}

The few molecular cytogenetic studies of ESCC cell lines reported to date indicate that these cell lines are highly abnormal cytogenetically. In a study in which eight ESCC cell lines were screened using mCGH, SKY and FISH with single probes, the pooled $\mathrm{CGH}$ results revealed frequent 
gains in almost all chromosome arms (1p, 1q, 3q, 5p, 6p, $7 \mathrm{p}, 7 \mathrm{q}, 8 \mathrm{q}, 9 \mathrm{q}, 11 \mathrm{q}, 12 \mathrm{p}, 14 \mathrm{q}, 15 \mathrm{q}, 16 \mathrm{p}, 16 \mathrm{q}, 17 \mathrm{q}, 18 \mathrm{p}, 19 \mathrm{q}$, $20 \mathrm{q}, 22 \mathrm{q}$ and $\mathrm{Xq}$ ), with frequent losses on $3 \mathrm{p}, 4,5 \mathrm{q}, 6 \mathrm{q}, 7 \mathrm{q}$, $9 \mathrm{p}$ and $18 \mathrm{q}$. SKY analyses detected 195 translocations, 13 deletions and two duplications in the eight cell lines, with the most frequently amplified genes being PIK3CA (3q26) and TP63 (3q28). PIK3CA encodes the catalytic subunit of phosphatidylinositol 3-kinase (PIK3), which uses ATP to phosphorylate phosphatidylinositol (National Center for Biotechnology Information, 2009a) and TP63 encodes a protein involved in the development and maintenance of stratified epithelial tissues (National Center for Biotechnology Information, 2009b). These oncogenes were amplified in six and five cell lines, respectively (Yen et al., 2003).

Multiple gains and losses involving different chromosomal regions were also revealed by $\mathrm{mCGH}$ in ten ESCC cell lines of the KYSE series (TE 1-6, 8-11, 13, and 15). The most frequent losses were observed on chromosomal arms 3p, 4p, 4q, 8p, 9p, 18q and Xp, whereas the most common gains were noted on 1q, 3q, 5p, 7p, 8q, 9q, 11q, 18p, $20 \mathrm{q}$ and Xq. While focal loss was only identified at $11 \mathrm{q} 23-$ 25 , focal amplifications were detect at 1q32, 2p16-22, 3q25-28, 5p13-15.3, 7p12-22, 7q21-22, 8q23-24.2, 9q34, $10 \mathrm{q} 21,11 \mathrm{p} 11.2,11 \mathrm{q} 13,13 \mathrm{q} 32,14 \mathrm{q} 13-14,14 \mathrm{q} 21,14 \mathrm{q} 31-$ 32, 15q22-26, 17p11.2, 18p11.2-11.3 and 20p11.2 (Shinomiya et al., 1999; Pimkhaokham et al. 2000; Su et al., 2006).

Yang et al. (2008a) recently reported cytogenetic abnormalities in the cell line KYSE 410-4 using M-FISH, with chromosomal gains on $2 \mathrm{q}, 3,8,17 \mathrm{p}$ and $\mathrm{X}$. An isochromosome $3 q$ was detected in this line and may represent an intermediate mechanism involved in $3 p$ loss and $3 q$ gain. For the cell line KYSE 180, M-FISH analysis detected loss of DNA copy number on chromosomes 4p, 5q, 6q, 9, 10p, 12 p, 13, 14p, 15p, 18p, 18q, 20, 22 and Y, and chromosomal gains and translocations mainly on chromosomes 1 , 2p, 3, 4p, 5p, 5q, 6p, 7, 8, 10q, 11, 12q, 14q, 16, 17q, 19 and $\mathrm{Xp}$. Seven derivative chromosomes involving chromosomes 5, 8, 12, 14, 15, 16, and 17 showed complex translocations, each involving three or four chromosomes; a loss of chromosomes 9, 13, and Y was also detected ( $\mathrm{Wu}$ et al., 2006).

Based on previous CGH studies that showed frequent amplifications in $18 \mathrm{p}$ in esophageal cell lines (Shimada et al., 1992; Pimkhaokham et al., 2000), Nakakuki et al. (2002) used FISH to screen 29 ESCC cell lines and identified amplifications of 14 known genes and 21 uncharacterized transcripts in chromosome 18 amplicons. These authors also investigated the corresponding levels of gene expression by Southern-, dot- and northern-blotting. Only four known genes (YES1, TYMS, HEC and TGIF) showed amplification and corresponding over-expression. YES1 encodes a protein with tyrosine kinase activity, TYMS is critical for DNA replication and repair, $H E C$ is involved in spindle checkpoint signaling and TGIF is a highly con- served transcription regulator with a potential role in the transmission of nuclear signals during development and in adults. These findings suggested that these genes are involved in 18p11.3 amplification and may be associated with esophageal tumorigenesis.

Figure 1A summarizes these studies. The alterations detected affected most of the genome and involved regions harboring many known oncogenes and tumor suppressor genes, as well regions not yet associated with such genes. Although the level of molecular resolution of most of these studies is low and inconclusive, these findings are promis-

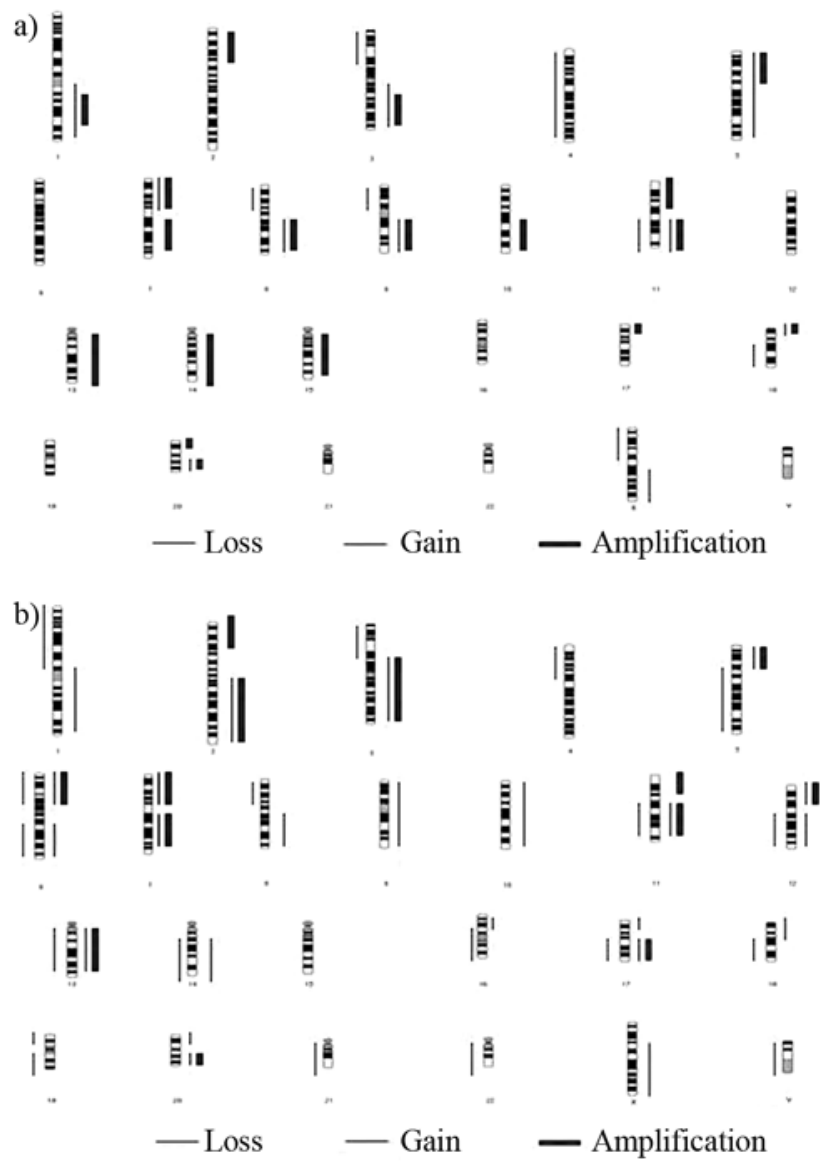

Figure 1 - Summary of copy number alterations in esophageal squamous cell carcinomas (ESCC) analyzed by comparative genomic hybridization. Regions with copy number gains are represented by thin lines on the right side of the chromosome idiograms and amplifications are represented by thick bars on the same side; regions of loss are represented by thin lines on the left side of the idiograms. (A) In ESCC cell lines, the most frequent genomic gains were observed in chromosomes 1, 2q, 3q, 5p, 6p, 7, 8q, 9q, 11q, 12p, 14, 15, 16, 17, 18p, 19q, 20q, 22q and X. Focal amplifications were found at $1 \mathrm{q} 32,2 \mathrm{p} 16-22,3 \mathrm{q} 25-28,5 \mathrm{p} 13-15.3,7 \mathrm{p} 12-22,7 \mathrm{q} 21-22$, 8q23-24.2, 9q34, 10q21, 11p11.2, 11q13, 13q32, 14q13-14, 14q21, 14q31-32, 15q22-26, 17p11.2, 18p11.2-11.3 and 20p11.2. Recurrent losses occurred at 3p, 4, 5q, 6q, 7q, 8p, 9, 10p, 12p, 13, 14p, 15p, 18, 20, 22, Xp and Y. (B) In clinical specimens, chromosomal gains were common in 1q, 2q, 3q, 5p, 6, 7, 8q, 9, 10, 11q, 12, 13q, 14q, 16p, 17, 18q, 20 and Xq, specifically in the regions $1 \mathrm{p} 34,2 \mathrm{p} 24,2 \mathrm{q} 24-34,3 \mathrm{q} 22$-ter, $7 \mathrm{p} 12$ 22, 8q13-qter, 11p11.2, 11q13, 12p11.2, 13q21-34, 17q12, 20q12-13 and Xq27-28. Recurrent losses occurred at 1p, 3q, 4p, 5q, 6, 8p, 11q, 12q, 13q, 14q, 16q, 17q, 18q, 19, 21q, 22q and Y. 
ing in that they provide a starting point for further investigations on the molecular pathogenesis of ESCC and the development of new therapeutic approaches for such cancer.

\section{Genomic Imbalances In Escc Tumors}

Despite advances in our understanding of the risk factors and cellular derangements associated with esophageal cancer, the clinical treatment of this disease remains largely unaltered and long-term survival from this cancer remains poor, with a 5-year survival rate of $\sim 20 \%$ (Hsia et al., 2003).

A combination of FISH, mCGH and aCGH has shown that chromosomes $1,3,7,9,11,18,19$ and 20 have a high frequency of alterations. In addition, genomic profiles of primary carcinomas have revealed imbalances affecting most of the chromosomes, such as gains on 1q, 3q, $5 p, 7 p$, 8q, 11q, 13q, 18p, 20q and Xq, and losses on 1p, 3p, 4p, 8p, $9 p, 18 q, 19,22 q$ and $Y$. Focal losses at 9p13, focal gains at $5 \mathrm{p} 15,8 \mathrm{p} 12-11.2,8 \mathrm{q} 24,11 \mathrm{q} 13$ and $14 \mathrm{q} 32$, and amplifications at 1p34, 2p24, 2q24-34, 3q22-ter, 7p12-22, 8q13-qter, $11 \mathrm{p} 11.2,11 \mathrm{q} 13,12 \mathrm{p} 11.2,13 \mathrm{q} 21-34,17 \mathrm{q} 12,20 \mathrm{q} 12-13$ and Xq27-28 are also commons findings (Pack et al., 1999; Shinomiya et al., 1999; Mayama et al., 2000; Yen et al., 2001; Kamitani et al., 2002; Yen et al., 2003; Kwong et al., 2004; Qin et al., 2004, 2005a,b, 2008; Sugimoto et al., 2007). High-level amplifications have been observed in 30 regions and repeatedly involve $7 \mathrm{p} 11.2$ and $11 \mathrm{q} 13$. The major gene amplified in the first of these regions is EGFR, which encodes the epidermal growth factor receptor (EGFR); activation of this receptor by its ligand results in dimerization and tyrosine auto-phosphorylation that leads to cell proliferation (Carneiro et al., 2008; National Center for Biotechnology Information, 2009c). The second of these regions harbors $C C N D 1$, a regulator of $\mathrm{CDK}$ kinases required for the G1/s cell cycle transition (Carneiro et al., 2008; National Center for Biotechnology Information, 2009d). Interstitial deletions in 1p, 3p, 5q, 6q, 11q and 12q have also been detected (Pack et al., 1999).

Together, these observations indicate that chromosomal aberrations are common in clinical ESCC specimens and suggest that chromosomes 1q, 3q, 5p, 6q, 8q,18p and $20 \mathrm{q}$, particularly regions $1 \mathrm{p} 34,2 \mathrm{p} 24,2 \mathrm{q} 24-34,3 \mathrm{q} 22$-ter, 7p12-22, 8q13-qter, 11p11.2, 11q13, 12p11.2, 13q21-34, 17q12, 20q12-13 and Xq27-28, may contain ESCC-related oncogenes; on the other hand, chromosomes 1p, 3p, 4p, 8p, 9p13, 9q and 19p may contain ESCC-related tumor suppressor genes involved in the development and progression of esophageal cancer (Figure 1B).

\section{Early Genomic Changes and Imbalances Associated With Tumor Staging}

ESCC arises through multi-step genetic and cytogenetic alterations. However, the time sequence of these al- terations remains to be determined. In this regard, studies in which chromosomal aberrations are correlated with the stage and clinical outcome of prognostic significance are necessary in order to facilitate the selection of patients for specific treatments.

An interesting recent study explored the usefulness of M-FISH for the early diagnosis and risk prediction of precursor lesions of ESCC in tumor and premalignant lesions in 113 patients (Yao et al., 2008). Elevated rates of aneuploidy were frequently observed in chromosomes $3,8,10$, 12,17 and 20 in ESCC and its precursor dysplastic lesions. These findings support the conclusion that the application of a multi-target FISH assay to investigate chromosomal aneuploidy at esophageal dysplastic sites may be useful in predicting the risk of ESCC.

The progression of dysplastic lesions to the advanced, metastatic stage is accompanied by numerous genomic changes, as indicated by mCGH analyses of ESCC lymph node metastasis. Copy number gains have frequently been detected at 1q, 1p36.32, 3q, 5p, 8q23-qter, 11q13-14, 5p14-pter, 6p, 20q, 7p22.3, 7q, 2p, 12p, 19p13.3 and 20p, and DNA amplifications have been detected at 11q13, 2q12, 6p12-6q12, 7q21, 20q11.2 and 20p12; losses have been detected at 18q, 3p, 9p, 5q14-23, 4q, 13 and 11q22qter (Qin et al., 2005a; Wang et al., 2006; Carneiro et al., 2008; Qin et al., 2008).

Gains involving 3q, 5p, 1q and 11q13-14 and losses involving 4 and $13 \mathrm{q}$ are significantly correlated with the pathological stage, whereas a gain of $8 q$ and loss of $4 p$ are linked to nodal metastasis; similarly, a gain of $2 p$ and loss of 4 and 11q14-qter are associated with distant organ metastasis (Qin et al., 2004). Gains involving 1q, 3q, 5p and 11q13-14 and losses involving 4 and 13q are critical for the development of ESCC, whereas a gain of $2 p$ and $8 q$ and loss of 4 and 11q14-qter are later events associated with tumor progression and thought to confer metastatic potential to the disease. Nodal and distant organ metastases apparently involve different genes (Qin et al., 2005b). Gains involving $3 \mathrm{q}$ and $11 \mathrm{q} 13$ and losses involving $3 \mathrm{p}, 4 \mathrm{q}, 5 \mathrm{q} 14-23$, $9 \mathrm{p}$ and $18 \mathrm{q}$ have been detected in early and advanced stages of ESCC.

Deletions of $4 p$ and 13q12-q14 and a gain of $5 p$ are significantly correlated with the pathological state. Losses of $8 \mathrm{p} 22$-pter and $9 \mathrm{p}$ are more frequent in patients with advanced disease. A gain of 8q24-qter is more frequent in patients with grade 3 tumors (Yen et al., 2001). Using mCGH, Shiomi et al. (2003) observed that gains involving 3q, 8q, $11 \mathrm{q} 13$ and $14 \mathrm{q}$ were early events, while the loss of $3 \mathrm{p}, 5 \mathrm{q}$, $13 q$ and $21 q$ and gain of $1 p$ and Xq were later events in the development of individual tumors.

Gains of $6 p$ and $20 p$ and losses of $10 p$ and $10 q$ are the most significant imbalances in primary carcinoma and metastasis, which suggests that these regions may harbor oncogenes and tumor suppressor genes (Qin et al., 2005a). 
A gain of 12p and loss of $3 p$ has been associated with poor relapse-free survival (Kwong et al., 2004).

\section{The Search For Relevant Oncogenes In Escc}

In 41 primary ESCC investigated with CGH (Fujita et al. 2003), the expression of numerous genes, including the cell cycle-regulator kinase gene BTAK (20q13.2-3) and $E 2 F 1$ (20q11.2), which plays a crucial role in cell cycle regulation, was enhanced in $\sim 10 \%$ of tumors. Other genes, such as NCOA3 (20q12), which encodes a nuclear receptor co-activator that enhances the transcriptional activator function of nuclear hormone receptors, and DcR3 (20q13.3), which regulates apoptosis were up-regulated to a lesser extent. $\mathrm{Xu}$ et al. (2007) detected NCOA3 overexpression and an increased copy number in $46 \%$ and $13 \%$ of 221 ESCCs, respectively. NCOA3 overexpression was observed more frequently in late compared to early stages, but there was no significant association between the expression of NCOA3 and lymph node metastases. These observations suggest that overexpression of $N C O A 3$ as a result of genomic gain or other molecular mechanisms might provide a selective advantage for the development and local invasion of certain subsets of ESCC.

To date, there has been no detailed analysis of loss of heterozygosity $(\mathrm{LOH})$ for chromosome $18 \mathrm{q}$ in ESCC. However, $\mathrm{LOH}$ on chromosome 18q is common in several cancers, with frequencies of 55\%-67\% in colorectal cancer (Jen et al., 1994; Thiagalingam et al., 1996), 90\% in pancreatic cancer (Hahn et al., 1996), 59\% in ovarian cancer (Lassus et al., 2001) and 40\%-84\% in head and neck squamous cell carcinoma (Papadimitrakopoulou et al., 1998; Pearlstein et al., 1998; Takebayashi et al., 2000). In these cancers, frequent $\mathrm{LOH}$ on chromosome $18 \mathrm{q}$ correlates with tumor growth, aggressive tumor behavior and tumorigenesis. These findings suggest that chromosome 18q may harbor tumor suppressor genes for various cancers (Ando et al., 2007). In a FISH analysis of the allelic imbalance of chromosome 18q in ESCC resected samples from two out of five patients showed a loss of one copy of chromosome $18 \mathrm{q}$, and 13 of 46 ESCC samples (28.3\%) showed loss of almost all of chromosome 18q (Ando et al., 2007). The authors suggested that the loss of $18 \mathrm{q}$ may play an important role in the progression of ESCC.

Few studies have focused on the identification of altered pathways and clinically applicable markers. Oncogene amplification was examined by DNA microarrays in 20 surgically resected ESCC and 57 oncogenes were found to be amplified. Alterations in DNA copy number detected by microarrays were compared to those obtained by mCGH. DNA microarrays showed that eight oncogenes (CCND1, FGF3/ FGF4, EMS1, SAS, ERBB2, PDGFRA, $M Y C$ and $B C L 2$ ) were amplified in 9 of 20 tumors. Although $E R B B 2$ expression was 23 -fold greater than the basal level in one case, the average level of gene amplification was generally only $2-4$-fold above the control value.
EMS1, $C C N D 1$ and $F G F 3 / F G F 4$, which are all located on $11 \mathrm{q} 13$, were amplified in 7, 5 and 4 of $20 \mathrm{ESCC}$, respectively, and were co-amplified in three tumors. EMS1 regulates the interactions between components of adherens-type junctions and organizes the cytoskeleton and cell adhesion structures of epithelia and carcinoma cells (National Center for Biotechnology Information, 2009e). FGF3/FGF4 broadly regulate mitogenesis, cell survival and oncogenic activity.

A comparison of genomic DNA microarray and mCGH data showed that although most of the amplified oncogenes were included in chromosomal regions for which gains in DNA copy number were detected by mCGH, not all of the amplified genes detected by microarrays showed concomitant gains in the DNA copy number in $\mathrm{mCGH}$; this lack of correlation between the two techniques confirmed the limited resolution of the $\mathrm{mCGH}$ assay. Microarrays of oncogenes are useful for the comprehensive identification of amplified oncogenes and for analyzing specific chromosomal regions in which $\mathrm{mCGH}$ analysis indicates an increase in DNA copy number (Arai et al., 2003).

FISH assays revealed the amplification of PLK1 (polo-like kinase 1), an essential gene for the maintenance of genomic stability during mitosis (Feng et al., 2009); this gene may therefore be a useful prognostic marker. An analysis of 108 ESCCs and nine ESCC cell lines revealed a frequent gain of the genes $M D S 1$ (myelodysplasia syndrome 1) and $P R K C I$ (protein kinase $\mathrm{C}$, iota), which have been implicated in neoplastic transformation, and a positive correlation between the level of PRKCI expression and tumor size, lymph node metastasis and clinical stage. PRKCI gene amplification was highly correlated with protein overexpression (Yang et al., 2008b).

EGFR expression is enhanced in many cancers and is sometimes accompanied by gene amplification. FISH analysis has shown that the EGFR gene is amplified in ESCC (Sunpaweravong et al., 2005; Hanawa et al., 2006). Indeed, $E G F R$ gene overrepresentation (balanced gene and chromosome 7 polysomy) and HER-2 amplification are common events in ESCC (Mimura et al., 2005; Sunpaweravong et al., 2005; Bizari et al., 2006).

Cyclin D1 $(C C D N 1)$ is a cell-cycle regulator and oncogene implicated in the pathogenesis of numerous types of tumors. Amplification of the CCDN1 gene is common in ESCC and has been detected by FISH (Sheyn et al., 1997; Jin et al., 2004; Manoel-Caetano et al., 2004; Sunpaweravong et al., 2005; Bizari et al., 2006).

The correlation between the overexpression and amplification of oncogenes and patient survival has not been extensively investigated. However, the survival of patients with increased expression of $B T A K$ or $E 2 F 1$ is significantly lower than that of patients without this alteration, which suggests that overexpression of these genes probably increases the number of malignant ESCC phenotypes and 
may be a useful marker of poor prognosis (Fujita et al., 2003).

\section{Concluding Remarks}

Various molecular cytogenetic approaches have been used to demonstrate the extensive genetic complexity associated with the different stages of ESCC and have identified key genes involved in esophageal cancer. Most of the unbalanced chromosomal regions are similar in primary tumors and cell lines, thus confirming that cell lines provide a reliable model for investigating the molecular mechanisms involved in ESCC.

Specific chromosomal imbalances are associated with the progression of esophageal tumors. Whereas gains in 1q, 5p, 8q, 14q and losses in 4p, 13q and 18q are associated with the early stages of ESCC development, gains in $1 \mathrm{p}, 2 \mathrm{p}, 7 \mathrm{p} 22.3,8 \mathrm{q}, 8 \mathrm{q} 24-\mathrm{qter}$ and $\mathrm{Xq}$ and losses in 8p22pter, $11 \mathrm{q} 14-\mathrm{qter}, 13 \mathrm{q}$ and $21 \mathrm{q}$ are associated with advanced stages. Gains involving 3q and 11q13 and losses involving $3 p, 4 q, 5 q 14-23,9 p$ and $18 q$ are detected in both early and advanced stages of ESCC. These regions harbor genes associated with essential cellular processes, such as signal transduction, transcriptional regulation, cell proliferation and cell differentiation, involved in signalizing cascades related to cancer. Some imbalances, such as losses involving $4 \mathrm{p}, 9 \mathrm{p}$ and $11 \mathrm{q}$ and gains involving $1 \mathrm{p} 36-32,5 \mathrm{p}, 7 \mathrm{q}$ and 19 p13.3, are poor prognostic markers. Gene overexpression most frequently affects oncogenes such as YES1, TYMS, HEC, TGIF, NCOA3, BTAK, DCR3, E2F1, MYC, EGFR, EGR2, CCND, FGF3/FGF4, EMS1, SAS, ERBB2, PDGFR1, BCL2, MDS1 and PRKCI, whereas genomic losses lead to the deletion of suppressor tumor genes such as CDKN2A, MTAP and TP53. Identification of the role of these critical genes in esophageal carcinogenesis will assist the development of individualized target therapy that should in turn improve the clinical outcome of ESCC patients.

\section{References}

Ando T, Ishiguro H, Kimura M, Mitsui A, Mori Y, Sugito N, Tomoda K, Mori R, Harada K, Katada T et al. (2007) Frequent loss of the long arm of chromosome 18 in esophageal squamous cell carcinoma. Oncol Rep 17:1005-1011.

Arai H, Ueno T, Tangoku A, Yoshino S, Abe T, Kawauchi S, Oga A, Furuya T, Oka M and Sasaki K (2003) Detection of amplified oncogenes by genome DNA microarrays in human primary esophageal squamous cell carcinoma: Comparison with conventional comparative genomic hybridization analysis. Cancer Genet Cytogenet 146:16-21.

Bauman JG, Wiegant J, Borst P and van Duijn P (1980) A new method for fluorescence microscopical localization of specific DNA sequences by in situ hybridization of fluorochromelabelled RNA. Exp Cell Res 128:485-490.

Bizari L, Borim AA, Leite KR, Gonçalves F de T, Cury PM, Tajara EH and Silva AE (2006) Alterations of the CCND1 and HER-2/neu (ERBB2) proteins in esophageal and gastric cancers. Cancer Genet Cytogenet 165:41-50.

Carneiro A, Isinger A, Karlsson A, Johansson J, Jönsson G, Bendahl PO, Falkenback D, Halvarsson B and Nilbert M (2008) Prognostic impact of array-based genomic profiles in esophageal squamous cell cancer. BMC Cancer 8:98-107.

Crawford JM (2004) The gastrointestinal tract. In: Cotran RS, Kumar V and Collins (eds) The Pathologic Basis of Disease. 7th edition. WB Saunders Company, Philadelphia, pp 775-787.

Daigo Y and Nakamura Y (2008) From cancer genomics to thoracic oncology: Discovery of new biomarkers and therapeutic targets for lung and esophageal carcinoma. Gen Thorac Cardiovasc Surg 56:43-53.

D'Amico TA (2006) Molecular biologic staging of esophageal cancer. Thorac Surg Clin 16:317-327.

du Manoir S, Speicher MR, Joos S, Schröck E, Popp S, Döhner H, Kovacs G, Robert-Nicoud M, Lichter P and Cremer T (1993) Detection of complete and partial chromosome gains and losses by comparative genomic in situ hybridization. Hum Genet 90:590-610.

Feng YB, Lin DC, Shi ZZ, Wang XC, Shen XM, Zhang Y, Du XL, Luo ML, Xu X, Han YL et al. (2009) Overexpression of PLK1 is associated with poor survival by inhibiting apoptosis via enhancement of survivin level in esophageal squamous cell carcinoma. Int J Cancer 124:578-588.

Fiegler H, Carr P, Douglas EJ, Burford DC, Hunt S, Scott CE, Smith J, Vetrie D, Gorman P, Tomlinson IP et al. (2003) DNA microarrays for comparative genomic hybridization based on DOP-PCR amplification of BAC and PAC clones. Genes Chromosomes Cancer 36:361-374.

Fujita Y, Sakakura C, Shimomura K, Nakanishi M, Yasuoka R, Aragane H, Hagiwara A, Abe T, Inazawa J and Yamagishi H (2003) Chromosome arm 20q gains and other genomic alterations in esophageal squamous cell carcinoma, as analyzed by comparative genomic hybridization and fluorescence in situ hybridization. Hepatogastroenterology 50:1857-1863.

Hahn SA, Schutte M, Hoque AT, Moskaluk CA, da Costa LT, Rozenblum E, Weinstein CL, Fischer A, Yeo CJ, Hruban RH et al. (1996) DPC4, a candidate tumor suppressor gene at human chromosome 18q21.1. Science 271:350-353.

Hanawa M, Suzuki S, Dobashi Y, Yamane T, Kono K, Enomoto $\mathrm{N}$ and Ooi A (2006) EGFR protein overexpression and gene amplification in squamous cell carcinomas of the esophagus. Int J Cancer 118:1173-1180.

Hsia JY, Chen CY, Chen JTA, Hsu CP, Shai SE, Yang SS, Chuang CY, Wang PY and Miaw J (2003) Prognostic significance of caspase-3 expression in primary resected esophageal squamous cell carcinoma. Eur J Surg Oncol 29:44-48.

Jen J, Kim H, Piantadosi S, Liu ZF, Levitt RC, Sistonen P, Kinzler KW, Vogelstein B and Hamilton SR (1994) Allelic loss of chromosome $18 \mathrm{q}$ and prognosis in colorectal cancer. N Engl J Med 331:213-221.

Jin Y, Jin C, Law S, Chu KM, Zhang H, Strombeck B, Yuen AP and Kwong YL (2004) Cytogenetic and fluorescence in situ hybridization characterization of clonal chromosomal aberrations and CCND1 amplification in esophageal carcinomas. Cancer Genet Cytogenet 148:21-28.

Kallioniemi A, Kallioniemi OP, Sudar D, Rutovitz D, Gray JW, Waldman F and Pinkel D (1992) Comparative genome hy- 
bridization for molecular cytogenetics analysis of solid tumors. Science 258:818-821.

Kamitani S, Sugihara H, Shiomi H, Tani T and Hattori T (2002) Intratumoral regional variations in copy number of the chromosomal part revealed by microdissection and combined ploidy and comparative genomic hybridization analyses in esophageal squamous cell carcinoma. Cancer Genet Cytogenet 132:30-35

Khushalani N (2008) Cancer of the esophagus and stomach. Mayo Clin Proc 83:712-722.

Knudson AG (1985) Hereditary cancer, oncogenes, and antioncongenes. Cancer Res 45:1437-1443.

Koch WM, Boyle JO, Mao L, Hankim J, Hruban RH and Sidransky D (1994) TP53 gene mutations as markers of tumor spread in synchoronous oral cancer. Arch Otolaryngol Head Neck Surg 120:943-947.

Kuwano H, Kato H, Miyazaki T, Fukuchi M, Masuda N, Nakajima M, Fukai Y, Sohda M, Kimura H and Faried A (2005) Genetic alterations in esophageal cancer. Surg Today 35:7-18.

Kwong KF (2005) Molecular biology of esophageal cancer in the genomics era. Surg Clin N Am 85:539-553.

Kwong D, Lam A, Guan X, Law S, Tai A, Wong J and Sham J (2004) Chromosomal aberrations in esophageal squamous cell carcinoma among Chinese: Gain of $12 p$ predicts poor prognosis after surgery. Hum Pathol 35:309-316.

Lam AK (2000) Molecular biology of esophageal squamous cell carcinoma. Crit Rev Oncol Hematol 33:71-90.

Langer PR, Waldrop AA and Ward DC (1981) Enzymatic synthesis of biotin-labeled polynucleotides: Novel nucleic acid affinity probes. Proc Natl Acad Sci USA 78:6633-6637.

Lassus H, Salovaara R, Aaltonen LA and Butzow R (2001) Allelic analysis of serous ovarian carcinoma reveals two putative tumor suppressor loci at 18q22-q23 distal to SMAD4, SMAD2 and DCC. Am J Pathol 159:35-42.

Mandard AM, Hainaut P and Hollstein M (2000) Genetic steps in the development of squamous cell carcinoma of the esophagus. Mutat Res 462:335-342.

Manoel-Caetano F da S, Borim AA, Caetano A, Cury PM and Silva AE (2004) Cytogenetic alterations in chagasic achalasia compared to esophageal carcinoma. Cancer Genet Cytogenet 149:17-22.

Mayama T, Fukushige S, Shineha R, Nishihira T, Satomi S and Horii A (2000) Frequent loss of copy number on the long arm of chromosome 21 in human esophageal squamous cell carcinoma. Int J Oncol 17:245-252.

McCabe ML and Dlamini Z (2005) The molecular mechanisms of oesophageal cancer. Int Immunopharmacol 5:1113-1130.

Mimura K, Kono K, Hanawa M, Mitsui F, Sugai H, Miyagawa N, Ooi A and Fujii H (2005) Frequencies of HER-2/neu expression and gene amplification in patients with oesophageal squamous cell carcinoma. Br J Cancer 92:1253-1260.

Muñoz N (1997) Le déspistage du cancer de I'oesophage est-il réalisable? Sem Hôp Paris 73:633-635.

Nakakuki K, Imoto I, Pimkhaokham A, Fukuda Y, Shimada Y, Imamura M, Amagasa T and Inazawa J (2002) Novel targets for the $18 \mathrm{p} 11.3$ amplification frequently observed in esophageal squamous cell carcinoma. Carcinogenesis 23:19-24.

Pack SD, Karkera JD, Zhuang Z, Pak ED, Balan KV, Hwu P, Park WS, Pham T, Ault DO, Glaser M et al. (1999) Molecular cytogenetic fingerprinting of esophageal squamous cell car- cinoma by comparative genomic hybridization reveals a consistent pattern of chromosomal alterations. Genes Chromosomes Cancer 25:160-168.

Papadimitrakopoulou VA, Oh Y, El-Naggar A, Izzo J, Clayman G and Mao L (1998) Presence of multiple incontiguous deleted regions at the long arm of chromosome 18 in head and neck cancer. Clin Cancer Res 4:539-544.

Pearlstein RP, Benninger MS, Carey TE, Zarbo RJ, Torres FX, Rybicki BA and Dyke DL (1998) Loss of 18q predicts poor survival of patients with squamous cell carcinoma of the head and neck. Genes Chromosomes Cancer 21:333-339.

Pimkhaokham A, Shimada Y, Fukuda Y, Kurihara N, Imoto I, Yang ZQ, Imamura M, Nakamura Y, Amagasa T and Inazawa J (2000) Nonrandom chromosomal imbalances in esophageal squamous cell carcinoma cell lines: Possible involvement of the $A T F 3$ and $C E N P F$ genes in the 1q32 amplicon. Jpn J Cancer Res 91:1126-1133.

Pinkel D, Segraves R, Sudar D, Clark S, Poole I, Kowbel D, Collins C, Kuo WL, Chen C, Zhai Y et al. (1998) High resolution analysis of DNA copy number variations using comparative genomic hybridization to microarrays. Nat Genet 20:207-211

Qin YR, Wang LD, Kwong D, Guan XY, Zhuang ZH, Fan ZM, An JY and Tsao G (2004) Comparative genomic hybridization of esophageal squamous cell carcinoma and gastric cardia adenocarcinoma in high-incidence region of esophageal carcinoma, Linzhou Henan. Zhonghua Yi Xue Yi Chuan Xue Za Zhi 21:625-628.

Qin YR, Wang LD, Dora K, Guan XY, Zhuang ZH, Fan ZM, Deng W and Cao SH (2005a) Genomic changes in primary lesion and lymph node metastases of esophageal squamous cell carcinoma. Ai Zheng 24:1048-1053.

Qin YR, Wang LD, Kwong D, Gao SS, Guan XY, Zhuang ZH, Fan ZM, Deng W and Hu L (2005b) Comparative genomic hybridization: The profile of chromosomal imbalances in esophageal squamous cell carcinoma. Zhonghua Bing Li Xue Za Zhi 34:80-83.

Qin YR, Wang LD, Fan ZM, Kwong D and Guan XY (2008) Comparative genomic hybridization analysis of genetic aberrations associated with development of esophageal squamous cell carcinoma in Henan, China. World J Gastroenterol 14:1828-1835.

Schröck E and Padilla-Nash H (2000) Spectral karyotyping and multicolor fluorescence in situ hybridization reveal new tumor-specific chromosomal aberrations. Sem Hematol 37:334-347

Schröck E, du Manoir S, Veldman T, Schoell B, Wienberg J, Ferguson-Smith MA, Ning Y, Ledbetter DH, Bar-Am I, Soenksen D et al. (1996) Multicolor spectral karyotyping of human chromosomes. Science 273:494-497.

Sherry ST, Ward MH, Kholodov M, Baker J, Phan L, Smigielski EM and Sirotkin K (2001) dbSNP: The NCBI database of genetic variation. Nucleic Acids Res 29:308-311.

Sheyn I, Noffsinger AE, Heffelfinger S, Davis B, Miller MA and Fenoglio-Preiser CM (1997) Amplification and expression of the cyclin D1 gene in anal and esophageal squamous cell carcinomas. Hum Pathol 28:270-276.

Shimada Y, Imamura M, Wagata T, Yamaguchi $\mathrm{N}$ and Tobe $\mathrm{T}$ (1992) Characterization of 21 newly established esophageal cancer cell lines. Cancer 69:277-284. 
Shinomiya T, Mori T, Ariyama Y, Sakabe T, Fukuda Y, Murakami Y, Nakamura Y and Inazawa J (1999) Comparative genomic hybridization of squamous cell carcinoma of the esophagus: The possible involvement of the DP1 gene in the 13q34 amplicon. Genes Chromosomes Cancer 24:337-344.

Shiomi H, Sugihara H, Kamitani S, Tokugawa T, Tsubosa Y, Okada K, Tamura H, Tani T, Kodama M and Hattori T (2003) Cytogenetic heterogeneity and progression of esophageal squamous cell carcinoma. Cancer Genet Cytogenet 147:50-61.

Snijders AM, Nowak N, Segraves R, Blackwood S, Brown N, Conroy J, Hamilton G, Hindle AK, Kimura K, Law S et al. (2001) Assembly of microarrays for genome-wide measurement of DNA copy number. Nat Genet 29:263-264.

Solinas-Toldo S, Lampel S, Stilgenbauer S, Nickolenko J, Benner A, Döhner H, Cremer T and Lichter P (1997) Matrix-based comparative genomic hybridization: Biochips to screen for genomic imbalances. Genes Chromosomes Cancer 20:399407.

Somers KD and Schechter GL (1992) Genetic alterations in head and neck cancer. Mol Biol Genet 25:1065-1071.

Speicher MR and Carter NP (2005) The new cytogenetics: Blurring the boundaries with molecular biology. Nature 6:782-792.

Speicher MR, Ballard SG and Ward DC (1996) Karyotyping human chromosomes by combinatorial multi-fluor FISH. Nat Genet 12:368-375.

Su M, Chin SF, Li XY, Edwards P, Caldas C and Fitzgerald RC (2006) Comparative genomic hybridization of esophageal adenocarcinoma and squamous cell carcinoma cell lines. Dis Esophagus 19:10-14.

Sugimoto T, Arai M, Shimada H, Hata A and Seki N (2007) Integrated analysis of expression and genome alteration reveals putative amplified target genes in esophageal cancer. Oncol Rep 18:465-472.

Sunpaweravong P, Sunpaweravong S, Puttawibul P, Mitarnun W, Zeng C, Barón AE, Franklin W, Said S and Varella-Garcia M (2005) Epidermal growth factor receptor and cyclin D1 are independently amplified and overexpressed in esophageal squamous cell carcinoma. J Cancer Res Clin Oncol 131:111-119.

Tada K, Oka M, Hayashi H, Tangoku A, Oga A and Sasaki K (2000) Cytogenetic analysis of esophageal squamous cell carcinoma cell lines by comparative genomic hybridization: Relationship of cytogenetic aberrations to in vitro cell growth. Cancer Genet Cytogenet 117:108-112.

Takebayashi S, Ogawa T, Jung KY, Muallem A, Mineta H, Fisher SG, Grenman R and Carey TE (2000) Identification of new minimally lost regions on $18 \mathrm{q}$ in head and neck squamous cell carcinoma. Cancer Res 60:3397-3403.

Thiagalingam S, Lengauer C, Leach FS, Schutte M, Hahn SA, Overhauser J, Willson JK, Markowitz S, Hamilton SR, Kern SE et al. (1996) Evaluation of candidate tumour suppressor genes on chromosome 18 in colorectal cancers. Nat Genet 13:343-346.

Wang LD, Qin YR, Fan ZM, Kwong D, Guan XY, Tsao GS, Sham J, Li JL and Feng XS (2006) Comparative genomic hybridization: Comparison between esophageal squamous cell carcinoma and gastric cardia adenocarcinoma from a high-incidence area for both cancers in Henan, northern China. Dis Esophagus 19:459-467.
Wu YP, Yang YL, Yang GZ, Wang XY, Luo ML, Zhang Y, Feng YB, Xu X, Han YL, Cai Y et al. (2006) Identification of chromosome aberrations in esophageal cancer cell line KYSE180 by multicolor fluorescence in situ hybridization. Cancer Genet Cytogenet 170:102-107.

Xu FP, Xie D, Wen JM, Wu HX, Liu YD, Bi J, Lv ZL, Zeng YX and Guan XY (2007) SRC-3/AIB1 protein and gene amplification levels in human esophageal squamous cell carcinomas. Cancer Lett 245:69-74.

Xue LY, Hu N, Song YM, Zou SM, Shou JZ, Qian LX, Ren LQ, Lin DM, Tong T, He ZG et al. (2006) Tissue microarray analysis reveals a tight correlation between protein expression pattern and progression of esophageal squamous cell carcinoma. BMC Cancer 6:296-311.

Yang YL, Chu JY, Wu Y, Luo ML, Xu X, Han YL, Cai Y, Zhan Q and Wang M (2008a) Chromosome analysis of esophageal squamous cell carcinoma cell line KYSE 410-4 by repetitive multicolor fluorescence in situ hybridization. J Genet Genomics 35:11-16.

Yang YL, Chu JY, Luo ML, Wu YP, Zhang Y, Feng YB, Shi ZZ, $\mathrm{Xu} \mathrm{X}$, Han YL, Cai Y et al. (2008b) Amplification of PRKCI, located in $3 q 26$, is associated with lymph node metastasis in esophageal squamous cell carcinoma. Genes Chromosomes Cancer 47:127-136.

Yao HQ, He S, Wu YP, Wang XC, Han YL, Xu X, Cai Y, Wang GQ and Wang MR (2008) Application of multicolor fluorescence in situ hybridization to early diagnosis of esophageal squamous cell carcinoma. Ai Zheng 27:1137-1143.

Yen CC, Chen YJ, Chen JT, Hsia JY, Chen PM, Liu JH, Fan FS, Chiou TJ, Wang WS and Lin CH (2001) Comparative genomic hybridization of esophageal squamous cell carcinoma: Correlations between chromosomal aberrations and disease progression/prognosis. Cancer 92:2769-2777.

Yen CC, Chen YJ, Lu KH, Hsia JY, Chen JT, Hu CP, Chen PM, Liu JH, Chiou TJ, Wang WS et al. (2003) Genotypic analysis of esophageal squamous cell carcinoma by molecular cytogenetics and real-time quantitative polymerase chain reaction. Int J Oncol 23:871-881.

\section{Internet Resources}

American Cancer Society, http://www.cancer.org/docroot/CRI/content/CRI_2_4_1X_What are the key_statistics_for_esophagus_cancer_12.asp? ${ }_{-}$sitearea $=($September 10, 2009).

Genome, National Human Genome Research Institute, http://www.genome.gov/Pages/Hyperion/DIR/VIP/Glossary/Illustration/fish.cfm?key = fluorescence $\% 20$ in $\% 20$ situ $\% 20$ hybridization $\% 20$ (FISH) (January 20, 2009).

Instituto Nacional do Câncer (INCA), http://www.inca.gov.br/conteudo_view.asp?id = 328 (September 10, 2009a).

http://www.inca.gov.br/estimativa/2008/index.asp?link = tabelaestados.asp\&UF = BR (September 10, 2009b).

Medical Genetics Laboratories, http://www.bcm.edu/geneticlabs/tests/cyto/105Kcma.html (December 22, 2008).

National Center for Biotechnology Information, http://www.ncbi.nlm.nih.gov/gene/5290?ordinalpos = 
2\&itool $=$

EntrezSystem2.PEntrez.Gene.Gene_ResultsPanel.Gene_R VDocSum (September 10, 2009a).

http://www.ncbi.nlm.nih.gov/gene/8626?ordinalpos = 1\&itool = EntrezSystem2.PEntrez.Gene.Gene_ResultsPanel.Gene_R VDocSum (September 10, 2009b).

http://www.ncbi.nlm.nih.gov/gene/1956?ordinalpos = 2\&itool = EntrezSystem2.PEntrez.Gene.Gene_ResultsPanel.Gene_R VDocSum (September 10, 2009c). http://www.ncbi.nlm.nih.gov/gene/595?ordinalpos = 1\&itool = EntrezSystem2.PEntrez.Gene.Gene_ResultsPanel.Gene_R VDocSum (September 10, 2009d).

http://www.ncbi.nlm.nih.gov/gene/2017?ordinalpos $=2 \&$ itool $=$ EntrezSystem2.PEntrez.Gene.Gene_ResultsPanel.Gene_R VDocSum (September 10, 2009e).

\section{Associate Editor: Emmanuel Dias Neto}

License information: This is an open-access article distributed under the terms of the Creative Commons Attribution License, which permits unrestricted use, distribution, and reproduction in any medium, provided the original work is properly cited. 